\title{
Oral and Intranasal Immunization with Recombinant Food-Grade Lactococcus Lactis Expressing High Conserved Region of SARS-CoV-2 Spike Protein Triggers Immunity Responses in Mice
}

\author{
Valentina Yurina ( $\nabla$ v_yurina@ub.ac.id ) \\ Universitas Brawijaya https://orcid.org/0000-0003-4319-942X \\ Oktavia Rahayu Adianingsih \\ Universitas Brawijaya \\ Nashi Widodo \\ Universitas Brawijaya
}

\section{Research}

Keywords: bacterial vector, vaccine, spike, intranasal, antibody

Posted Date: October 11th, 2021

DOl: https://doi.org/10.21203/rs.3.rs-951426/v1

License: (c) (1) This work is licensed under a Creative Commons Attribution 4.0 International License.

Read Full License 


\section{Abstract}

Background: The COVID-19 pandemic began at the end of 2019 in Wuhan, China, and has spread throughout the world until mid-2021. Thus far, no specific therapy has been found for the coronavirus family. Vaccination still becomes the most effective prevention of pathogenic infections, including viral infections. However, little data show that this vaccination can protect against SARS-CoV-2 virus for a long time. Thus, revaccination needs to be regularly carried out to prevent the occurrence of COVID-19. Vaccination by injection is invasive, and it becomes one of the reasons people refuse to get revaccinated. Therefore, we developed a less invasive vaccine based on oral or nasal administration. The gene encoding the high conserved region (HCR) spike protein was inserted into pNZ8149 and expressed in $L$. lactis NZ3900.

Results: The results of nasal and oral administration in experimental animals showed that L. lactis carrying the HCR gene could induce a humoral immune response, as indicated by an increasing IgG and IgA against SARS-CoV-2 (IgG/IgA-SARS-CoV-2) levels and the lymph cell population after nasal and oral vaccination in mice $(p<0.05)$.

Conclusion: This study shows promising results that can be developed into a less invasive alternative to nasal and oral vaccination.

\section{Background}

Coronaviruses are a large family of viruses that cause mild to moderate upper respiratory tract infections. However, several types of coronavirus are also causing more severe diseases, such as the Middle East respiratory syndrome (MERS-CoV), severe acute respiratory syndrome (SARS-CoV), and coronavirus disease 2019 (COVID-19) [1]. The SARS-CoV-2 is a member of the coronaviridae family, which until the mid of 2021, has infected more than 180 million people and caused more than 4 million deaths worldwide. Moreover, within three months of its global spread, the SARS-CoV-2 has caused many losses in various sectors [2].

Severe acute respiratory syndrome (SARS) is an acute respiratory tract disorder caused by a coronavirus (SARS-CoV). According to the World Health Organization (WHO), this disease caused 8400 cases and 900 deaths during the global outbreak in 2002/2003 [3]. The novel coronavirus, which has been spreading in Saudi Arabia since March 2012, has never been found in the world before and has different characteristics from the SARS coronavirus, which infected 32 countries in 2003 [4], although the Middle East respiratory syndrome coronavirus (MERS-CoV) is an emerging virus implicated in cases of acute respiratory infection in the Arabian Peninsula, Tunisia, Morocco, France, Italy, Germany, and the United Kingdom.

All types of coronaviruses cause clinical symptoms, including fever, cough, acute respiratory distress, pneumonia, fatigue, headache, dyspnea, lymphopenia, and sometimes gastrointestinal symptoms, such as diarrhea. Severe COVID-19 infection can be characterized by opacification in both subpleural areas of 
the lung, acute respiratory distress syndrome, and acute cardiac injury. In severe infections, local and systemic immune responses lead to severe inflammation [1, 2, 5]. Additionally, high-risk groups for coronavirus infection include the elderly (over 60 years), children, pregnant women, and people with immunocompromised and chronic diseases (diabetes mellitus, hypertension, heart, and respiratory disease).

Spike protein is a surface protein in coronavirus that plays a role in binding to receptors and facilitating membrane fusion. SARS-spike CoV-2's (S) protein is made up of two subunits, S1 and S2. The S1 subunit has a receptor-binding domain that identifies and binds to the host receptor angiotensin-converting enzyme 2, whereas the $S 2$ subunit promotes viral cell membrane fusion by producing a six-helical bundle through the two-heptad domain. The $\mathbf{2} 2$ protein also facilitates fusion between the virion and the cell membrane $[4,6]$.

The most effective way to prevent viral infections is vaccines. Several COVID-19 vaccines have been distributed with various efficacy levels. All of the approved vaccines are given by the parenteral route, which is invasive. Our study developed a mucosal route of vaccine through a live bacterial vector as the carrier. Lactic acid bacteria (LAB) are generally recognized as a safe class of bacteria used for centuries in food processing. The $L A B$ is also resistant to enzymatic reaction and extreme $\mathrm{pH}$ in the gastrointestinal area [7]. Induction of the mucosal immune system is vital in developing coronavirus vaccines because this type of virus infects via the mucosal route. The LAB used in this study is food grade and does not use antibiotics in the selection process, so it is safer to develop as a nutraceutical product.

This study successfully constructs the recombinant plasmid expressing a high conserved region of the SARS-CoV-2 spike protein and analyses its efficacy in serum IgG and IgA induction in mice. The novelty of this research is the selection of the highly conserved region of the spike protein S2 as a candidate for a coronavirus vaccine. An in silico study has been carried out to map the highly conserved region of the spike protein from nine different coronavirus strains [8]. To our knowledge, the study is the first study to show the efficacy of food grade bacterial vectors to deliver the SARS-CoV-2 vaccine candidate.

\section{Results}

\section{Construction of L. lactis NZ3900 pNZHCR and expression of spike HCR protein}

We constructed an HCR spike expression vector, in which the gene expression of HCR spike was controlled by a nisin-inducible promoter (Pnis) (Fig. 1A). The resulting plasmid was electroporated to $L$. lactis NZ3900. From several nisin concentrations added to the culture media, the $40 \mathrm{ng} / \mathrm{mL}$ concentration showed the best result from quantification methods using ELISA (data not shown). Western blotting is also shown by only one band corresponding to HCR spike protein. This result showed that nisin induced the expression of HCR peptides.

We tested whether oral and nasal immunization with $L$. lactis-pNZHCR could induce a humoral response by measuring the IgG and plasma cell (CD138+). Serum IgG against SARS-CoV-2 (IgG-SARS-CoV-2) was 
detected at 56 days after the first immunization (Figure 2A). A high IgG-SARS-CoV-2 response level was elicited when mice were immunized with pNZHCR oral and nasal compared to IgG levels produced by the L. lactis groups. High plasma cell levels were also detected in mice immunized with pNZHCR nasal compared to pNZHCR oral and L. lactis groups (Figure 2B). There was no significant difference in the sera of the mice immunized with pNZHCR oral compared to the L. lactis group.

\section{Oral and nasal immunization stimulated the mucosal immune response}

The IgA against SARS-CoV-2 (IgA-SARS-CoV-2) was also detected higher in mice given the oral and nasal of L. lactis-pNZHCR than control (L. lactis without plasmid) (Figure 3A). The mice immunized with HCR oral and nasal showed increased intestinal plasma cell but not those with oral administration after 56 days of first immunization (Figure 3B). These data indicate that the administration of L. lactis containing the plasmid encoding the HCR gene can improve the humoral immune system in experimental animals. This phenomenon is the beginning of a study to develop a non-invasive oral/nasal-based COVID-19 vaccine.

\section{Discussion}

All Covid-19 vaccines given are by injection, but the antibodies in the body could not last long. Several works of literature show that the antibodies cannot protect against SARS-CoV-2 infection post six months of vaccination [9], meaning that it is necessary to vaccinate periodically. Thus, we developed a vaccine possible to be administered via oral or nasal route, which is less invasive. The results of our study showed that $L$. lactis carrying the HCR plasmid after overexpression using nisin $40 \mathrm{ug} / \mathrm{ml}$ increased the production of $\mathrm{IgG}$ and $\operatorname{IgA}$ in the serum of experimental animals. This L. Lactis vaccine is food grade and safer because it uses a lactose selection system and does not use antibiotics. L. lactis has been widely tested as a therapeutic career $[10,11]$, including in vaccine delivery systems $[7,12]$.

This microbe-based vaccine is highly suitable when administered via the intranasal and oral routes, which is in line with the results of this study. Vaccines utilizing the mucosal route can activate various immune system pathways, including the mucosal immune system, through the production of slgA, serum IgG antibodies, and the cellular immune system. s-IgA is an antibody circulating on the surface of the mucosal layer and plays a role in preventing the attachment and invasion of pathogens and neutralizes enterotoxins. Serum IgG contributes to capturing invasive pathogens that enter through the mucosa or circulate systemically. Meanwhile, the response of the cellular immune system is involved against intracellular pathogens [13].

Nasal administration in this study showed better results than oral because nasal administration can increase the immune system respond better due to the enzymes' elimination mechanism in the digestive tract. It is in line with a previous study conducted by Blanchett et al., that showed an increased immune response of B cells and T cells in mice vaccinated with food-grade L. lactis expressing Ag85b protein [14]. 
Vaccination via the intranasal route will stimulate a different immune response than vaccination by the oral route, as Takaki et al. (2018) explained comprehensively. In vaccination via the intranasal route, there is an increasing mucosal immune response through the production of secretory- $\lg A(s-\lg A)$ in addition to a systemic immune response. S-IgA will provide extra protection before the virus penetrates the epithelial membrane of respiratory mucosal cells [15]. Furthermore, s-IgA can also provide cross-reactivity protection against other heterologous viruses [15]. This makes vaccination against SARS-CoV-2 via the intranasal route more advantageous because it could provide better protection against various SARSCoV-2 variants.

Further, in the respiratory tract of experimental animals, there is nasal-associated lymphoid tissue (NALT), which is similar to Waldeyer's ring and the adenoid, tubal, palatine, and lingual tonsils in humans. NALT has a different formation mechanism than the other mucosal immunity because NALT is formed after birth through an interaction mechanism with indigenous bacteria in the nasal cavity. The NALT system consists of several components of immune cells, including T cells, B cells, dendritic cells (DCs), macrophages, and microfold cells. NALT is also the first immune tissue exposed to inhalant antigens and pathogens, where pathogens trapped by DC will be carried by microfold cells to NALT. Pathogens exposed by DCs activate $T$ cells and induce the formation of cytokines suitable for IgA production at the inductive site of mucosal immunity. Then, there will be IgA switching and B cell maturation. Activated $T$ cells and IgA-producing B cells will be stored in the effector area, so these two types of immune cells can immediately provide protection when pathogen invasion occurs in the nasal area [16].

Measurement of serum IgA also showed similar results, and there was a higher increase in serum IgA levels when administered via the nasal route than the oral route. Other studies have also shown that administration of $L$. lactis via the mucosal route could increase serum IgA levels in experimental animals $[17,18]$.

Through oral route administration, L. lactis will be captured after entering the digestive system. The immune system will recognize the carrier bacteria on the surface of the gastrointestinal tract, especially by Microfold cells ( $\mathrm{M}$ cells) and dendritic cells. In the intestinal tract, dendritic cells have a special morphology, which has transepithelial dendrite that can penetrate the intestinal lumen [13]. Antigen will be carried across the intestinal epithelial barrier and delivered to the APC. Further, the activated APC will induce $\mathrm{CD} 4^{+} \mathrm{T}$ cells in germinal centers located in Peyer's Patches and mesenteric lymph nodes. CD $4^{+} \mathrm{T}$ cells will activate B cells, resulting in isotype switching that produces B cells [19].

The resulting B cells can be either antibody secreting plasma B cells (ASC) or memory B cells. Upon repeated exposure, memory $B$ cells will immediately differentiate into plasma $B$ cells that can secrete antibodies, either in the form of s-lgA on the mucosal surface or IgG on the systemic side. s-lgA on the mucosal surface contributes to recognizing and neutralizing antigens entering through the oral route. Meanwhile, plasma cells in the spleen or in the circulation play a role in producing IgG, which neutralizes pathogens entering the circulatory system [13]. 
One of the weaknesses in this study is the presence of $\operatorname{lgG} / \lg A$ levels that appear in the control, indicating that the possible nCov antibody that we use cannot specifically detect IgG, particularly against SARSCoV-2. Although, in general, the results of this study showed an acceptable rationale because the lgG levels in control and treatment were different, plasma B cells that produced antibodies would accumulate on the effector site close to the inductive site. Therefore, it is vital to administer vaccination by the route closest to where the pathogen will invade. Since SARS-CoV-2 invades through the respiratory route, vaccination via the intranasal route would be very beneficial.

\section{Conclusions}

Our study suggests that the recombinant $L$. lactis that expressed SARS-CoV-2 spike protein significantly increase the anti-spike SARS-CoV-2 antibody in mice. The intranasal vaccination gave higher antibody titer than oral route. Our study suggest that the intranasal vaccination using L.lactis as the carrier is promising as the new SARS-CoV-2 vaccine candidate.

\section{Material And Methods}

\section{SARS-CoV-2 pNZ-HCR constructs and transformations in Lactococcus lactis NZ3900}

The high conserved region (HCR) spike protein was chemically synthesized (GenScript, New Jersey, United States) and ligated with the pUC vector upon codon optimization for L. lactis. The plasmid was subcloned on Escherichia coli DH5a using the heat shock method at $42^{\circ} \mathrm{C}$ for 90 seconds. Bacterial cultures were grown on Luria Bertani Agar (1st BASE, Singapore) medium supplemented with ampicillin overnight. The next day, the plasmid was isolated using a DNA isolation kit (Thermo Fisher Scientific, Massachusetts, United States), and then the inserted gene was digested with $\mathrm{Kpnl}$ and EcolRI enzymes (Thermo Fisher Scientific, Massachusetts, United States). Following this, synthetic HCR was purified from the gel and ligated with pNZ8149 (MoBiTec GmbH, Goettingen Germany), the plasmid used for expression in L. lactis NZ3900 (MoBiTec GmbH, Goettingen Germany). The ligated plasmid was mixed with competent $L$. lactis NZ3900 cells. The mixture of plasmid and competent $L$. lactis cells was then electroporated using a Gene Pulser Xcell electroporation system (Bio-Rad Laboratories, Inc., Hercules, CA, USA) following the manufacturer's instructions at 2000V, 25 $\mu \mathrm{F}, 200 \Omega$. The cells were recovered by incubation at $30^{\circ} \mathrm{C}$ for $1.5-2$ hours, and the cells were spread on M17 Agar media (1st BASE, Singapore) supplemented with $0.5 \%$ lactose (Santa Cruz, Dallas, Texas, United States) as the selection medium and incubated for 24-48 hours. The clones were verified using PCR and the sequencing method (Macrogen, South Korea).

\section{Induction of SARS-CoV-2 spike protein expression in L. lactis NZ3900}

HCR spike gene expression was induced by supplementation of various nisin concentrations (MoBiTec $\mathrm{GmbH}$, Goettingen Germany) (Table 1) to indicate the optimal condition for protein expression. Various nisin concentrations $(10-40 \mathrm{ng} / \mathrm{mL})$ were added to the culture medium at the OD600 of around 0.8, 
followed by 18 hours incubation time at $30^{\circ} \mathrm{C}$. Bacterial cells and culture supernatants were separated by centrifugation, and the cells were sonicated five times. The expression of the spike protein was analyzed using SDS PAGE and Western Blot. Western blotting was performed using a primary antibody (Ab) against the SARS-CoV-2 spike protein $(0.5 \mathrm{ug} / \mathrm{mL}$, GenScript, New Jersey, USA), followed by incubation with a horseradish peroxidase-conjugated secondary Ab (1:100.000; Sigma, St. Louis, MO, USA).

\section{Animal treatment}

The experimental protocol was reviewed and approved by the Ethical Committee, Faculty of Medicine, Universitas Brawijaya (approval letter No. 205/EC/KEPK/12/2020). Six to eight-week-old C57BL/6 wildtype (WT) males were randomized to four different groups consisting of four mice, i.e., treated with $L$. lactis NZ3900, L. lactis pNZHCR (oral route), L. lactis pNZHCR (intranasal route). The animals were given free access to food and water during the experiment. The mice were maintained and eliminated according to the guidelines of the Institutional Ethics Committee.

Immunization was performed three times with a two-week interval in between, and each immunization was repeated for three consecutive days (day 1-3, 14-16, 28-30). Briefly, in each day, the treatment groups received $5 \times 10^{9} \mathrm{CFU}$ recombinant $L$. lactis for the oral route and $1 \times 10^{9} \mathrm{CFU}$ recombinant $L$. lactis for the intranasal route. On day 56 , the animals were anesthetized and sacrificed, and blood samples were obtained.

\section{Immunoglobulin measurements using ELISA}

Measurement of serum IgG and IgA levels was carried out using the mouse anti-2019-nCoV(S) IgG ELISA kit and the mouse anti-2019-nCoV(S) IgA ELISA kit (FineTest, Wuhan, Hubei, China) each plate was labeled with the primary antibody. The standard solution with serial concentration was prepared and diluted with sample dilution buffer (1:10). The microplate was washed twice with wash buffer and then added $50 \mu \mathrm{l}$ standard and diluted sample into each well. The plate was incubated at $37^{\circ} \mathrm{C}$ for 30 minutes and then washed three times with wash buffer. After washing, $50 \mu \mathrm{HRP}$-labeled antibody was added and incubated at $37^{\circ} \mathrm{C}$ for 30 minutes. The plate was washed five times with wash buffer. As much as $50 \mu l$ TMB substrate was added and incubated in the dark at $37^{\circ} \mathrm{C}$ for 10 minutes. The reaction was stopped by adding $50 \mu \mathrm{l}$ stop solution to each well, and the OD absorbance was read at $450 \mathrm{~nm}$ using an ELISA reader.

\section{Serum and Intestinal cell plasma analysis using flow cytometry}

Lymphocytes were isolated from the spleen by cutting the spleen into 2-4 parts, and $1 \mathrm{ml}$ of CSB buffer was added. Then, the spleen was crushed, and the connective tissue was separated using tweezers. The spleen suspension was filtered using a cell strainer, transferred to a tube, and then centrifuged (1500 rpm, $4^{\circ} \mathrm{C}, 3-5$ minutes). After the supernatant was discarded, the pellet was added with $1 \mathrm{ml}$ of RBC lysis buffer and incubated in the dark at room temperature. After 5 minutes, it was centrifuged $\left(1500 \mathrm{rpm}, 4^{\circ} \mathrm{C}, 3-5\right.$ 
minutes). The supernatant was then discarded, and the pellet was washed with $1 \mathrm{ml}$ of PBS. This process was repeated two times until there were no lumps.

Isolation of lymphocytes from the small intestine was done by removing the fat attached to the small intestine and then washed the lumen with $15-20 \mathrm{ml}$ of cold PBS. The small intestine was cut into 3-4 inches and slice lengthwise. The tissue was transferred to a container containing $30 \mathrm{ml}$ of extraction medium and stirred at $500 \mathrm{rpm}$ for 15 minutes at $37^{\circ} \mathrm{C}$. After the tissue was washed using RPMI to remove the residue, the tissue was transferred to a tube containing $600 \mu \mathrm{l}$ of digestive media and chopped. As much as $25 \mathrm{ml}$ of digestion media was added, then the tissue was stirred at $500 \mathrm{rpm}$ for 30 minutes at $37^{\circ} \mathrm{C}$. After stirring, the tissue was filtered using a cell strainer and added with $1 \mathrm{ml}$ of RPMI and $10 \% \mathrm{FBS}$. The suspension was centrifuged $\left(3000 \mathrm{rpm}, 4^{\circ} \mathrm{C}, 10\right.$ minutes) and resuspended the pellet with $1 \mathrm{ml}$ RPMI and 10\% FBS after removing the supernatant. The process was repeated once.

The harvested pellets containing isolated lymphocytes were added with $500 \mu$ of CSB buffer and divided into $50 \mu \mathrm{l}$ for further staining. The sample was added with $300 \mu \mathrm{l}$ of CSB buffer and CD138 antibody (Santa Cruz). It was then incubated at $4^{\circ} \mathrm{C}$ for 20 minutes in the dark and added $300 \mu$ of CSB buffer. Data were acquired using a flow cytometer.

\section{Statistical analysis}

The mean and standard deviation were used to present the data. The normality of the distribution of the investigated variables was assessed using the Shapiro-Wilk test and the Kolmogorov-Smirnov test. The student's t-test and the ANOVA test were used to analyze the statistical data, and p-values less than 0.05 were considered statistically significant. The analyses were performed using IBM ${ }^{\circledR} S P S S \AA$.

\section{Declarations}

\section{Ethics approval and consent to participate}

The experimental protocol was reviewed and approved by the Ethical Committee, Faculty of Medicine, Universitas Brawijaya (approval letter No. 205/EC/KEPK/12/2020).

The name of the ethics committee : http://fk.ub.ac.id/etik/profil/anggota-komisi-etik/

\section{Consent for publication}

Not applicable

\section{Availability of data and materials}

The datasets used and/or analysed during the current study are available from the corresponding author on reasonable request.

\section{Competing interests}


The authors declare that they have no competing interests.

\section{Funding}

This research is fully supported by Indonesia National Research and Innovation Agency / Badan Riset dan Inovasi (BRIN) and Indonesia Endowment Fund for Education/ Lembaga Pengelola Dana Pendidikan (LPDP) through COVID-19 Research Consortium Grant

\section{Authors' contributions}

VY: Conceived and designed the analysis, collected the data, contributed data or analysis tools, performed the analysis, wrote the paper

ORA: Collected the data, contributed data or analysis tools, wrote the paper

W: Contributed data or analysis tools, performed the analysis, wrote the paper

\section{Acknowledgements}

This research is supported by Indonesia National Research and Innovation Agency / Badan Riset dan Inovasi (BRIN) and Indonesia Endowment Fund for Education/ Lembaga Pengelola Dana Pendidikan (LPDP) through COVID-19 Research Consortium Grant.

\section{References}

1. Rothan HA, Byrareddy SN. The epidemiology and pathogenesis of coronavirus disease (COVID-19) outbreak. J Autoimmun [Internet]. Elsevier; 2020;102433. Available from: https://doi.org/10.1016/j.jaut.2020.102433.

2. Tsang HF, Chan LWC, Cho WCS, Yu ACS, Yim AKY, Chan AKC, et al. An update on COVID-19 pandemic: the epidemiology, pathogenesis, prevention and treatment strategies. Expert Rev Anti Infect Ther [Internet]. Taylor \& Francis; 2021;19:877-88. Available from: https://doi.org/10.1080/14787210.2021.1863146.

3. Xu RH, He JF, Evans MR, Peng GW, Field HE, Yu DW, et al. Epidemiologic clues to SARS origin in China. Emerg Infect Dis. 2004;10:1030-7.

4. Ahmed SF, Quadeer AA, McKay MR. Preliminary identification of potential vaccine targets for the COVID-19 Coronavirus (SARS-CoV-2) Based on SARS-CoV Immunological Studies. Viruses. 2020;12.

5. Xu Z, Shi L, Wang Y, Zhang J, Huang L, Zhang C, et al. Pathological findings of COVID-19 associated with acute respiratory distress syndrome. Lancet Respir Med [Internet]. Elsevier Ltd; 2020;2600:1921. Available from: http://dx.doi.org/10.1016/S2213-2600(20)30076-X.

6. Huang $Y$, Yang $C, X u X$ feng, Xu W, Liu S wen. Structural and functional properties of SARS-CoV-2 spike protein: potential antivirus drug development for COVID-19. Acta Pharmacol Sin [Internet]. Springer US; 2020;41:1141-9. Available from: http://dx.doi.org/10.1038/s41401-020-0485-4. 
7. Yurina V. Live Bacterial Vectors-A Promising DNA Vaccine Delivery System. Med Sci. 2018;6:27.

8. Yurina V. Coronavirus epitope prediction from highly conserved region of spike protein. Clin Exp Vaccine Res. 2020;9:169-73.

9. Baraniuk C. How long does covid-19 immunity last? BMJ. 2021;373:10-2.

10. Yumoto K, Sato T, Nakashima K, Namai F, Shigemori S, Shimosato T, et al. Nasally administered lactococcus lactis secreting heme oxygenase- 1 attenuates murine emphysema. Antioxidants. 2020;9:1-16.

11. Namai F, Shigemori S, Ogita T, Sato T, Shimosato T. Microbial therapeutics for acute colitis based on genetically modified Lactococcus lactis hypersecreting IL-1Ra in mice. Exp Mol Med [Internet]. Springer US; 2020;52:1627-36. Available from: http://dx.doi.org/10.1038/s12276-020-00507-5.

12. Wyszyńska A, Kobierecka P, Bardowski J, Jagusztyn-Krynicka EK. Lactic acid bacteria-20 years exploring their potential as live vectors for mucosal vaccination. Appl Microbiol Biotechnol. 2015;99:2967-77.

13. Ramirez K, Ditamo Y, Rodriguez L, Picking WL, van Roosmalen ML, Leenhouts $K$, et al. Neonatal mucosal immunization with a non-living, non-genetically modified Lactococcus lactis vaccine carrier induces systemic and local Th1-type immunity and protects against lethal bacterial infection. Mucosal Immunol [Internet]. Nature Publishing Group; 2010;3:159-71. Available from: http://www.pubmedcentral.nih.gov/articlerender.fcgi? artid=2863133\&tool=pmcentrez\&rendertype=abstract.

14. Blanchett S, Tsai CJ, Sandford S, Loh JM, Huang L, Kirman JRPT. Intranasal immunization with Ag85B peptide 25 displayed on Lactococcus lactis using the PilVax platform induces antigenspecific B- and T-cell responses. Immunol Cell Biol [Internet]. 2021;99:767-81. Available from: https://pubmed.ncbi.nlm.nih.gov/33866609/.

15. Sano K, Ainai A, Suzuki T, Hasegawa H. Intranasal inactivated influenza vaccines for the prevention of seasonal influenza epidemics. Expert Rev Vaccines [Internet]. Taylor \& Francis; 2018;17:687-96. Available from: https://doi.org/10.1080/14760584.2018.1507743.

16. Takaki H, Ichimiya S, Matsumoto M, Seya T. Mucosal Immune Response in Nasal-Associated Lymphoid Tissue upon Intranasal Administration by Adjuvants. J Innate Immun. 2018;10:515-21.

17. Diaz-Dinamarca DA, Hernandez C, Escobar DF, Soto DA, Muñoz GA, Badilla JF, et al. Mucosal vaccination with lactococcus lactis-secreting surface immunological protein induces humoral and cellular immune protection against group b streptococcus in a murine model. Vaccines. 2020;8.

18. Takahashi K, Yano A, Watanabe S, Langella P, Bermúdez-Humarán LG, Inoue N. M cell-targeting strategy enhances systemic and mucosal immune responses induced by oral administration of nuclease-producing L. lactis. Appl Microbiol Biotechnol Applied Microbiology Biotechnology. 2018;102:10703-11.

19. Vela Ramirez JE, Sharpe LA, Peppas NA. Current state and challenges in developing oral vaccines. Adv Drug Deliv Rev [Internet]. Elsevier B.V.; 2017;114:116-31. Available from: http://dx.doi.org/10.1016/j.addr.2017.04.008. 


\section{Figures}

A.

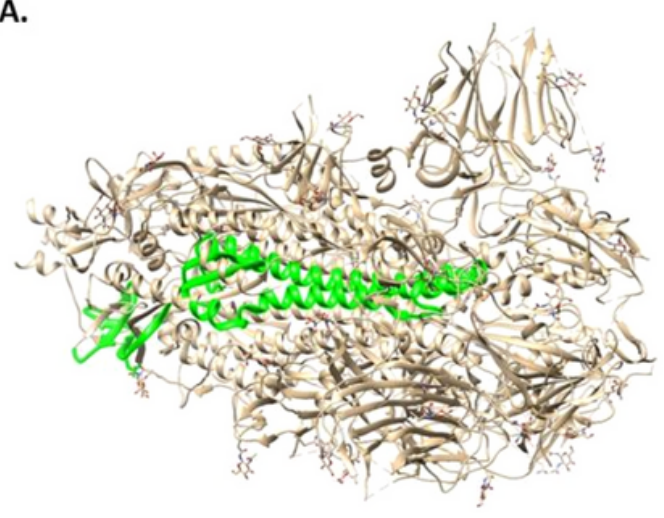

C.

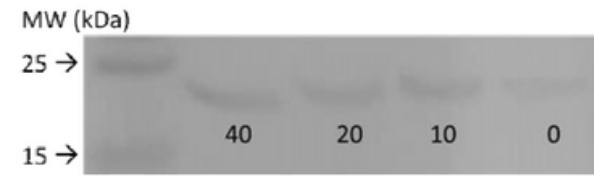

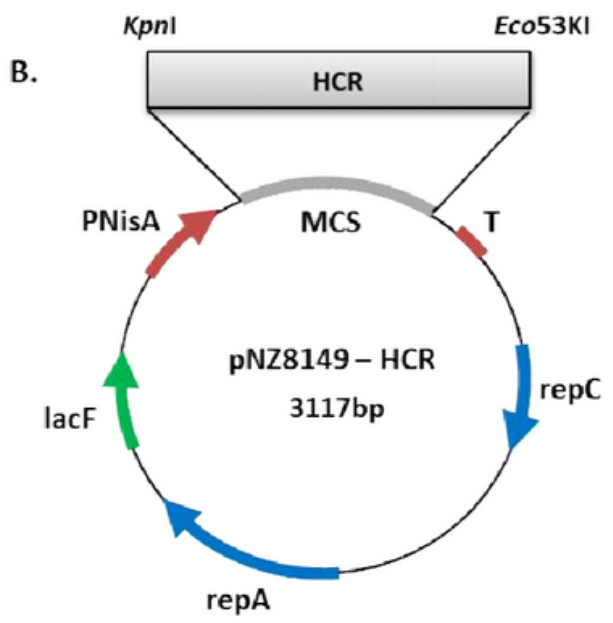

\section{Figure 1}

Diagram of HCR on full-length spike protein and Construction of pNZHCR. HCR is a conserved area and has antigenicity and epitope (light green) (A). pNZ8149-HCR (pNZHCR) with gene encoding SARS-CoV-2 spike HCR (567 bp) was inserted between Kpnl and Eco53KI. (B). Expression of spike HCR protein detected using anti-SARS-CoV-2 spike antibody (C). 

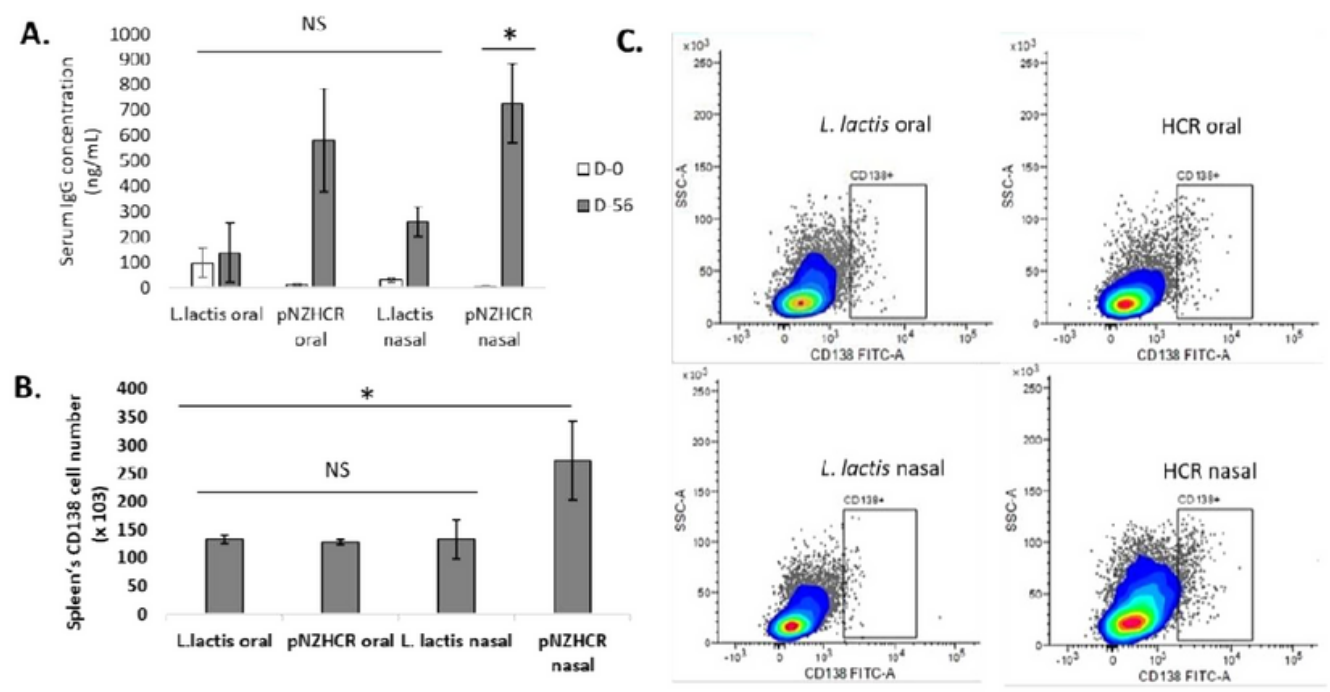

\section{Figure 2}

Administration of L. lactis-pNZHCR induced a humoral response in mice. The IgG-SARS-CoV-2 concentration was higher in mice given oral and nasal of L. lactis-pNZHCR compared to control (L. lactis without plasmid) (A). Moreover, the L. lactis-pNZHCR also induce Cd138 cell in the spleen (B), and Representative flow cytometry plots gated on live CD 138 spleen cells (C). NS: not significant. *Significantly different $(p<0.05)$ 

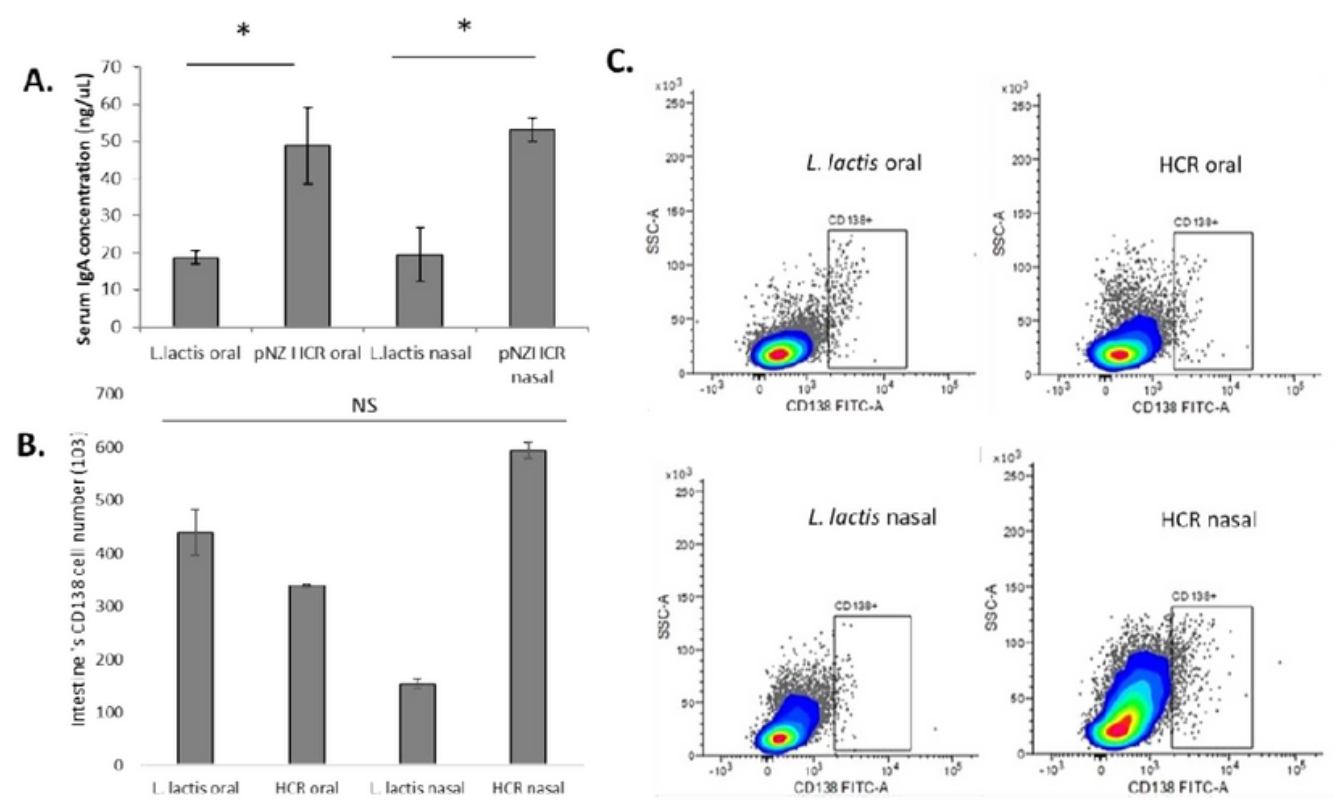

\section{Figure 3}

Administration both nasal and oral of L. lactis-pNZHCR induced IgA-HCR production in mice serum (A); and Cd138 cell in mice intestine (B), and Representative flow cytometry plots gated on live CD 138 spleen cells (C). NS: not significant. * Significantly different $(p<0.05)$ 